\title{
Oral contraceptives suppress cell proliferation and enhance apoptosis of eutopic endometrial tissue from patients with endometriosis
}

Received August 28, 2001; revised and accepted November 30, 2001.

This study was supported by ANPCYT (PICT 6384 BID 1201 OC-AR), UBA (01/TW05, University of Buenos Aires, Argentina), and the Roemmers Foundation, Buenos Aires, Argentina.

Reprint requests: Gabriela Meresman, Ph.D., Instituto de Biología y Medicina Experimental, Vuelta de Obligado 2490, Buenos Aires (1428), Argentina (FAX: 541-1-47862564; E-mail: meresman@dna. uba.ar).

a Instituto de Biología y Medicina Experimental (IBYME).

b Instituto de Ginecología y Fertilidad (IFER).

$0015-0282 / 02 / \$ 22.00$ PII S0015-0282(02)03099-6

\author{
Gabriela F. Meresman, Ph.D., ${ }^{\mathrm{a}}$ Luis Augé, M.D., ${ }^{\mathrm{b}}$ Rosa I. Barañao, Ph.D., ${ }^{\mathrm{a}}$ \\ Eduardo Lombardi, M.D., ${ }^{\mathrm{b}}$ Marta Tesone, Ph.D., ${ }^{\mathrm{a}}$ and Carlos Sueldo, M.D. ${ }^{\mathrm{b}}$ \\ Instituto de Biología y Medicina Experimental (IBYME) and Instituto de Ginecología y Fertilidad (IFER), Buenos \\ Aires, Argentina
}

Objective: To evaluate the effects of administering combination oral contraceptives (COCs) to patients with endometriosis on the regulation of cell growth in the eutopic endometrium.

Design: Prospective study.

Setting: Research institute and clinical fertility center.

Patient(s): Thirteen women with untreated endometriosis and 13 controls.

Intervention(s): Biopsy specimens of the eutopic endometrium were obtained from all subjects. Apoptosis, cell proliferation, and Bcl-2 and Bax expression were examined at the epithelial and stromal levels in the eutopic endometrium from patients with endometriosis before and after 30 days of daily exposure to COCs and from controls.

Main Outcome Measure(s): Apoptotic cells were detected by using the dUTP nick-end labeling assay; $\mathrm{Ki}-67, \mathrm{Bcl}-2$, and Bax expressions were assessed by using immunohistochemical techniques.

Result(s): After exposure to COCs, apoptosis was significantly increased in the eutopic endometrium compared with before COC administration, both at epithelial and stromal levels. Cell proliferation was significantly lowered by COCs.

Conclusion(s): COCs showed a positive effect on patients with endometriosis by down-regulating cell proliferation and enhancing apoptosis in the eutopic endometrium. (Fertil Steril ${ }^{\circledR} 2002 ; 77: 1141-7$. (C)2002 by American Society for Reproductive Medicine.)

Key Words: Oral contraceptives, endometriosis, eutopic endometrium, cell proliferation, apoptosis

During the menstrual cycle, the human endometrium goes through structural changes that are regulated by the different levels of sex steroid hormones. The cell proliferation of the endometrium is stimulated by $17 \beta$-estradiol, reaching its maximum level at ovulation time and then falling because of the effects of $\mathrm{P}(1)$. During menses, the uterine endometrium is shed in a type of tissue degeneration that involves a process of necrosis as well as apoptosis (2).

Apoptosis, or programmed cell death, plays an important role in the cyclic changes that take place during the menstrual cycle. This mechanism is coded genetically and contributes to the homeostasis of the tissues, estab- lishing an adequate balance between cell division and cell death (3). It has been shown that apoptosis of the endometrium is regulated by steroid hormones in different species, such as rabbits (4), hamsters (5), and monkeys (6).

Hopwood and Levinson showed for the first time changes in apoptosis of the glandular epithelium in the human endometrium throughout the menstrual cycle (2). More recent publications confirmed the presence of endometrial apoptosis, mainly in the late secretory phase of the menstrual cycle $(1,2,7,8)$.

Apoptosis is controlled by the expression of a number of regulatory genes that include, among others, the Bc1-2 (B cell lymphoma/ leukemia-2). This proto-oncogen promotes cell 
survival by blocking the apoptosis induced by different stimuli (9). The antiapoptotic properties of Bc1-2 depend on its interaction with a number of powerful antagonistic proteins, particularly the Bax protein, which antagonizes the survival activity promoted by $\mathrm{Bc} 1-2$. This proto-oncogen ( $\mathrm{Bc} 1-2)$ should form heterodimers with the Bax protein to exercise its action, and the relation $\mathrm{Bc} 1-2 / \mathrm{Bax}$ predetermines the cells susceptibility to a given apoptotic stimulant (10).

Endometriosis (EDT), defined as the presence of endometrial tissue outside the uterine cavity, is one of the most common benign disorders of the female pelvis during reproductive years. Recently, a number of studies reported that the eutopic endometrium from patients with EDT is ultimately responsible for the endometriotic implants (11). Recent work from our laboratory showed an increased survival capability in the eutopic endometrium from patients with EDT, both at the epithelial and stromal levels, possibly regulated by an increased effect of Bc1-2 (8).

Combination oral contraceptives (COCs) have been one of the treatment options for the medical management of EDT, especially after surgical ablation, to maintain the status quo and prevent progression or recurrence (12). They can also be administered cyclically as a first line of treatment for EDT-associated pelvic pain (13). Although the histological effects of COCs on the endometrium have been well studied (14), their action on the regulation of cell proliferation and apoptosis on the eutopic endometrium from patients with EDT is unknown and is the objective of this study.

\section{MATERIALS AND METHODS}

\section{Patients}

We studied a total of 26 female patients with regular ovulatory cycles who had not received any medical treatment for EDT in the previous 12 months.

Thirteen patients were diagnosed by laparoscopy as having histologically proven EDT. A control group (C) consisted of 13 women who underwent laparoscopic surgery for pelvic pain (uterine myomas, $\mathrm{n}=4$; ovarian cysts not related to EDT, $\mathrm{n}=4$; and unexplained pelvic pain $\mathrm{n}=5$ ) and who were found to be free of EDT.

This study was approved by the Institutional Review Board, and all subjects included in the study signed informed consent forms. Biopsy specimens of the eutopic endometrium (cycle days 7-10) were obtained from all subjects (including controls) as described elsewhere (15). Specimens were obtained from control patients during the laparoscopic procedures and from the patients with EDT after 30 days of

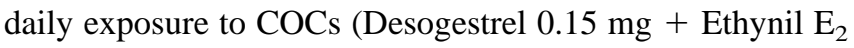
$30 \mu \mathrm{g}$ daily; Marvelon, Organon Argentina, Bs As, Argentina).

\section{Apoptosis Detection System}

Eutopic endometrial tissues were fixed in $10 \%$ buffered formaldehyde. For apoptosis quantification, tissue sections were processed for in situ immunocytochemical localization of nuclei exhibiting DNA fragmentation by the technique of terminal deoxynucleotidyl transferase (TdT)-mediated dUTP digoxygenin nick-end labeling (TUNEL), using an apoptosis detection kit (Intergen, Gaithersburg, MD). Sections were treated according to the manufacturer's instructions and as described elsewhere (8).

Briefly, sections were deparaffinized and rehydrated with xylene and ethanol and permeabilized with $20 \mu \mathrm{g} / \mathrm{mL}$ Proteinase K (Gibco, Grand Island, NY). Endogenous peroxidase was inactivated by coating the samples with $3 \% \mathrm{H}_{2} \mathrm{O}_{2}$. Sections were rinsed with PBS and then immersed for 60 minutes in TdT buffer at $37^{\circ} \mathrm{C}$. The appropriate dilution of this enzyme was determined in preliminary experiments. The sections were incubated for 30 minutes with the anti-digoxygenin peroxidase conjugate, followed by the peroxidase substrate (3'-diaminobenzidine tetrahydrochloride [DAB]). Finally, sections were counterstained with $0.5 \%(\mathrm{w} / \mathrm{v})$ methyl green. Sections of female rodent mammary gland obtained 3-5 days after weaning of pups were used as a positive control. As a negative control, a number of tissue samples were subjected to treatment without TdT. The number of apoptotic cells were determined by counting labeled cells at $630 \times$ magnification in 30 randomly selected and homogeneous fields and expressed as the apoptotic cell mean/field.

Apoptotic cells were identified by their characteristic morphological features in hematoxylin-eosin-stained endometrial sections. These features included cell shrinkage and chromatin margination or chromatin condensation with formation of apoptotic bodies (8).

\section{Immunohistochemical Staining}

Ki-67 was studied from the same paraffin-embedded samples as Bcl-2 and Bax on serial sections using an immunohistochemical method.

Sections were deparaffinized in xylene and rehydrated through graded alcohols, followed by microwaving in 0.01 $\mathrm{M}$ sodium citrate buffer for antigen retrieval. Endogenous peroxidase was blocked by treatment with $0.3 \%$ hydrogen peroxide for 30 minutes at room temperature, after which nonspecific binding was blocked by incubation with normal rabbit serum. Tissue sections were incubated for 60 minutes with anti-human Ki-67 rabbit monoclonal antibody (Dako Ltd., Cambridge, UK), anti-human Bcl-2 mouse monoclonal antibody (Dako Ltd.), or anti-human Bax rabbit polyclonal antibody (Dako Ltd.) at $37^{\circ} \mathrm{C}$, followed by incubation for 60 minutes with anti-mouse-peroxidase conjugate or anti-rabbit-peroxidase conjugate (Dako Ltd.). The Catayzed Signal Amplification System (Dako Ltd.) was used to amplify the intensity of Bax staining. Binding was visualized by incubating sections with $\mathrm{DAB}$ and lightly counterstaining with hematoxylin before permanent mounting.

Tonsil tissue was included as a positive control for Bax, and lymph node tissue as a positive control for Ki-67 and 
Bcl-2. As a negative control, immunoglobulin of the same immunoglobulin class and concentration as the primary antibody was used. The negative control showed an absence of specific staining. Ki-67-, Bcl-2-, and Bax-positive cells were identified by the presence of brown cellular reactivity. Immunoreactivity for Ki-67 is only expressed in dividing cells. The Ki-67 index can therefore be used as a marker of cell proliferation (1).

The number of cells expressing immunoreactivity for Ki-67 per 100 cells (Ki-67 index) was established by two independent observers using a standard light microscope. The total number of cells in 30 representative fields was counted separately in glandular epithelium and stroma. Any nuclear staining was regarded as positive, and no grading of staining intensity was done. There was no significant difference in results between the two observers $(P=.63)$.

The intensity of Bcl-2 and Bax staining was assessed in a blind fashion at $400 \times$ magnification by two independent observers whose results were concordant. A semiquantitative assessment method was used as described elsewhere $(8,16)$. Each observer viewed multiple randomly selected fields (n $=30$ ) of each tissue specimen and scored their staining intensity by grades. The intensity of staining was scored as $(-)$ negative, $(+)$ weakly positive, $(++)$ positive, and $(+++)$ strongly positive. The advantage of this method consists in its precise localization of the protein on the endometrial section, while at the same time enabling a correlation between the presence of apoptotic cells measured by the TUNEL method and Bcl-2/Bax expression.

\section{Statistics}

Statistical comparisons were performed by Kruskal-Wallis nonparametric analysis of variance, followed by Dunn's multiple comparison test. Regardless of the statistical test, only $P \leq .05$ was considered statistically significant.

\section{RESULTS}

\section{Ki-67 Expression in the Eutopic Endometrium}

The endometrial tissue at the epithelial (EP) and stromal (ST) levels from patients with EDT showed a significantly higher degree of cell proliferation in comparison with controls $(10.2 \pm 4.3$ vs. $2.0 \pm 0.8$, respectively, in EP, Fig. 1A; and $20.2 \pm 6.4$ vs. $6.0 \pm 2.5$, respectively, in ST, $P<.001$, Fig. 1B and Fig. 3A).

After exposure to COCs, the histological observation revealed an endometrial transformation toward atrophic changes, with scanty proliferation and with few glands. This morphologic appearance correlated with results in the Ki-67 index; after COC administration, we observed a significantly lower degree of cell proliferation compared with before COC administration at the EP and ST levels $(3.0 \pm 1$ vs. $10.2 \pm 4.3$ in EP and $9.2 \pm 2.3$ vs. $20.2 \pm 6.4$ in ST, $P<.05$ ) (Fig 1).

\section{FIGURE 1}

Cell proliferation at the EP $(\mathbf{A})$ and ST levels $(\mathbf{B})$ in eutopic endometria from patients with EDT before (EDT-PRE) and after (EDT-POST) COC administration and in control women (CONTROL). Histological sections were immunostained for $\mathrm{Ki}-67$ expression (see text). The Ki-67 index was determined by counting labeled cells in $400 \times$ randomly selected fields. Data were expressed as the number of EP cells expressing immunoreactivity for Ki-67 per 100 cells (Ki-67 index) (A) and as the number of cells expressing immunoreactivity for Ki-67 (positive) ST cells per field (B). ${ }^{\star} P<.001$ vs. EDT-PRE; ${ }^{\star \star} P<.05$ vs. EDT-PRE; EDT-POST vs. CONTROL, $P>05$.
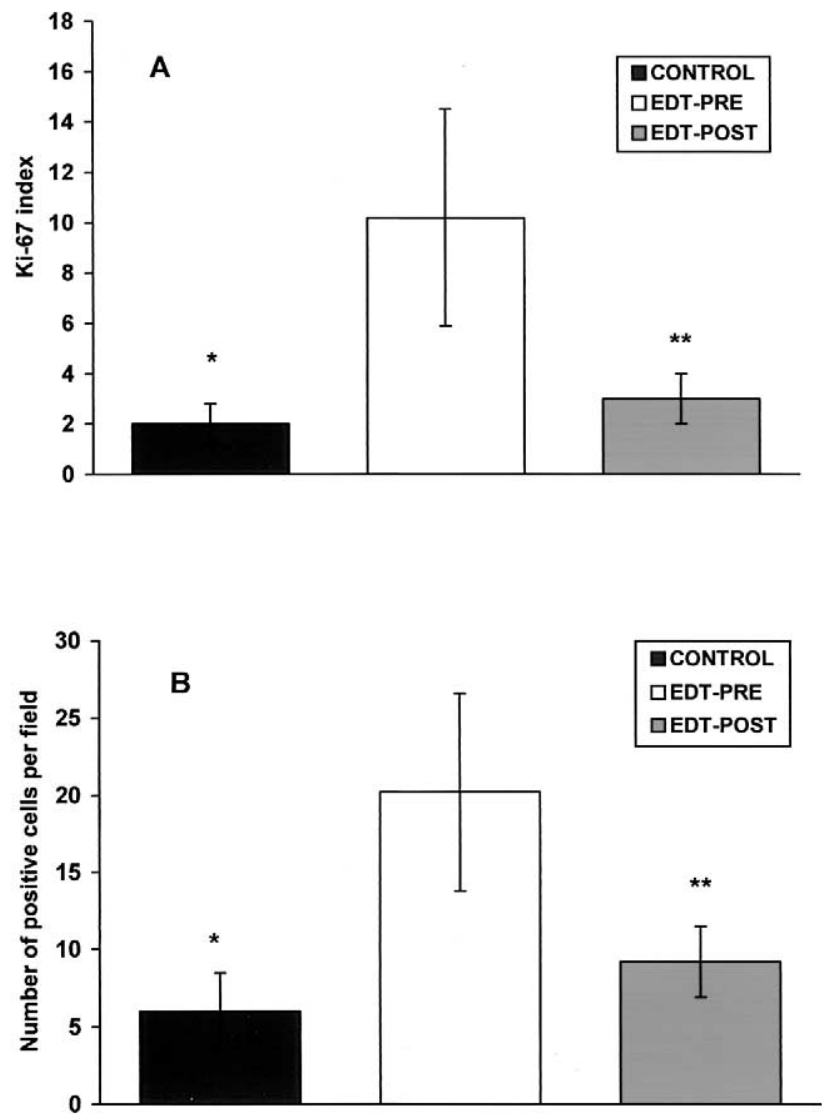

Meresman. Oral contraceptives and endometriosis. Fertil Steril 2002

We observed a normalization in cell proliferation by the Ki-67 index in EDT after COC, since the values were not significantly higher than in controls $(3.0 \pm 1$ vs. $2.0 \pm 0.8$, respectively, in EP and $9.2 \pm 2.3$ vs. $6.0 \pm 2.5$, respectively, in ST, $P>.05$ ) (Fig 1).

\section{Apoptosis in the Eutopic Endometrium}

There was a significantly lower level of apoptosis in patients with EDT in comparison with controls ( $0.9 \pm 0.3$ vs. $3.4 \pm 1.8$, respectively, at EP, Fig. $2 \mathrm{~A}$; and $7.6 \pm 3.1 \mathrm{vs}$. $15.1 \pm 4.3$, respectively, at ST, Fig. $2 \mathrm{~B}, P<.001)$. Patients with EDT showed a significant increment in apoptosis after 


\section{FIGURE 2}

Spontaneous apoptosis at the EP $(\mathbf{A})$ and ST levels $(\mathbf{B})$ in eutopic endometria from patients with EDT before (EDT-PRE) and after (EDT-POST) COC administration and in control women (CONTROL). Histological sections were immunostained by the TUNEL technique (see text). The numbers of apoptotic cells were determined by counting labeled cells in $630 \times$ randomly selected fields. Data were expressed as the apoptotic cell mean/field. ${ }^{\star} P<.001$ vs. EDT-PRE; ${ }^{\star \star} P<.05$ vs. EDT-PRE; EDT-POST vs. CONTROL, $P>.05$.
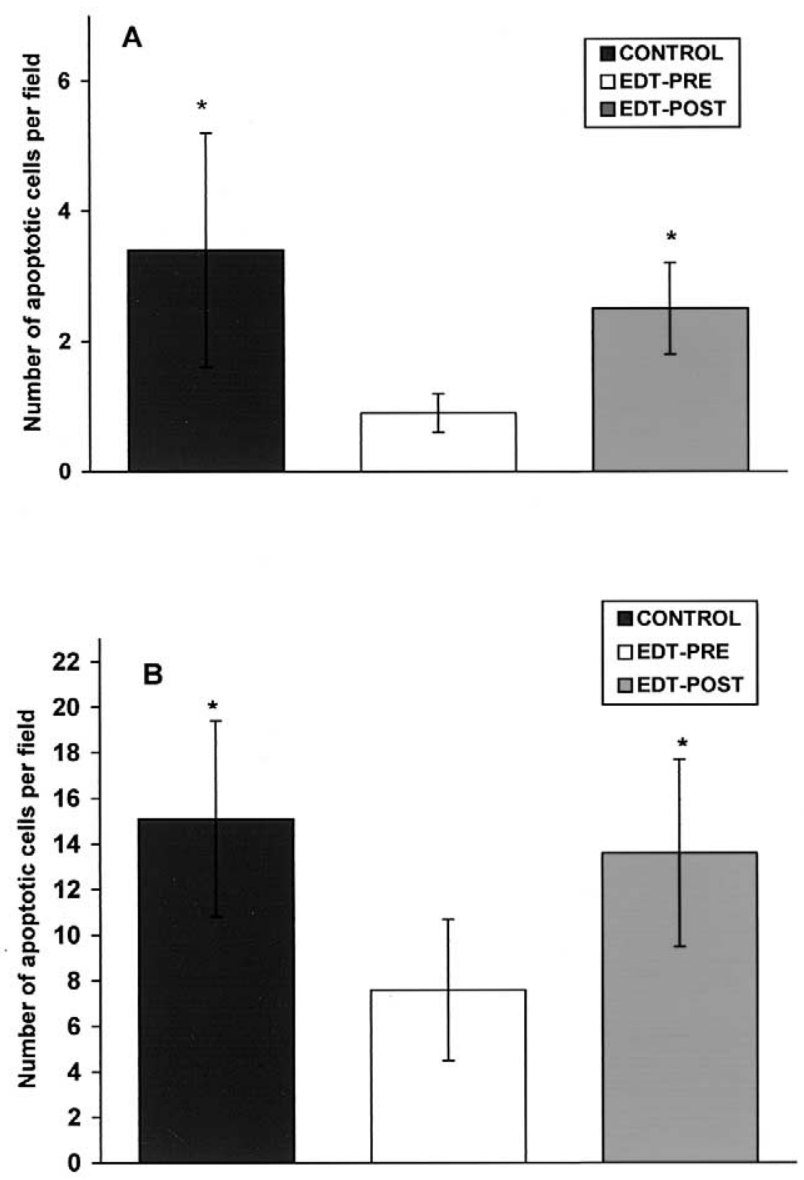

Meresman. Oral contraceptives and endometriosis. Fertil Steril 2002.

exposure to COC, both at the EP level $(2.5 \pm 0.7$ vs. $0.9 \pm$ $0.3 P<.05)$ and $\mathrm{ST}$ level $(13.6 \pm 4.1$ vs. $7.5 \pm 3.1, P<.05)$ (Fig. 2 and Fig. 3B).

Short-term exposure to COCs significantly increased the level of apoptosis in patients with EDT; the values are comparable to control patients at the ST level (13.6 \pm 4.1 vs. $15.1 \pm 4.3$, respectively, $P>.05)$ and at the EP level $(2.5 \pm$ 0.7 vs. $3.4 \pm 1.8$, respectively, $P>.05$ ) (Fig. 2 ).

\section{Bcl-2 and Bax Expression in the Eutopic Endometrium}

The endometrium from patients with EDT showed an increased expression of Bcl-2 compared with controls under
FIGURE 3

Representative photomicrograph of histological sections from the eutopic endometrium of women with EDT. Immunostaining of endometrial sections for cell proliferation by $\mathrm{Ki}-67$ expression before administering COCs (A) and for apoptosis by the TUNEL technique after COC administration (B) is shown. Note the presence of numerous immunostained cells. The original magnification was $\times 400$.
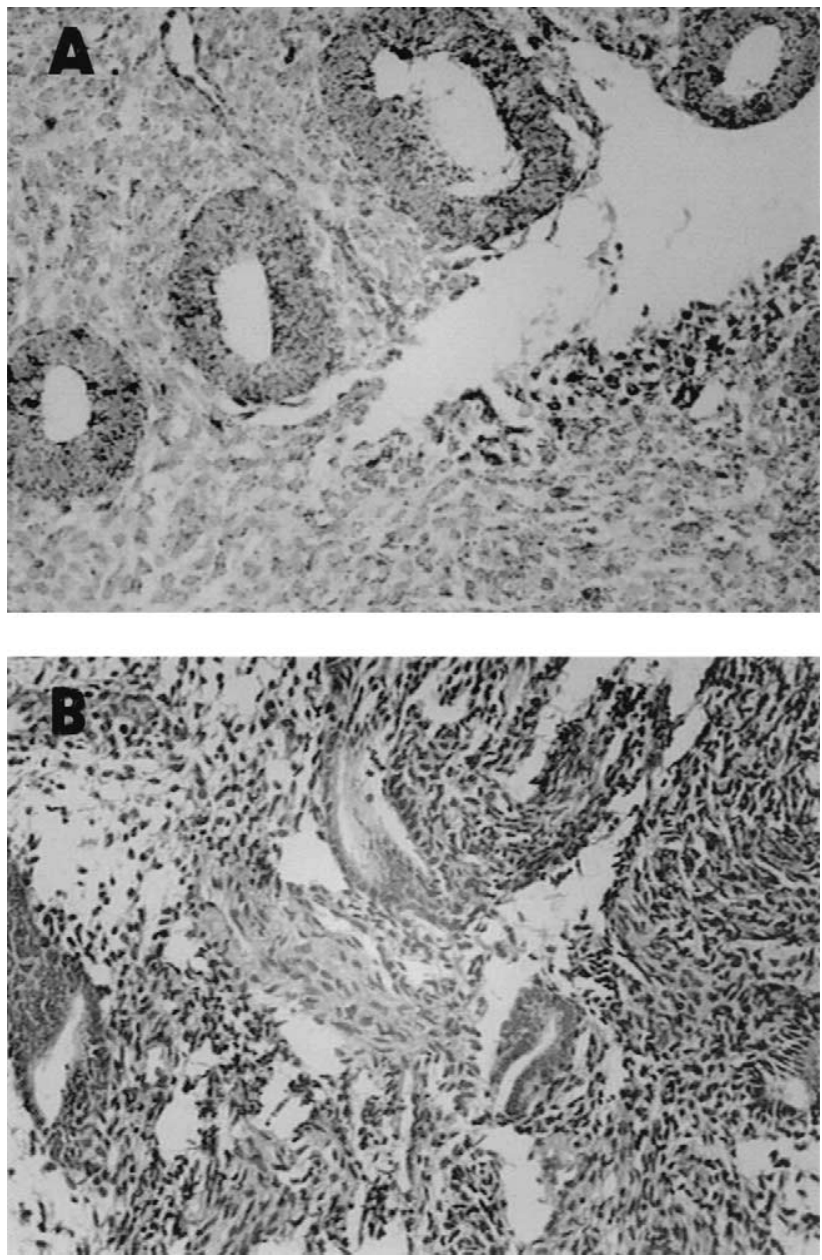

Meresman. Oral contraceptives and endometriosis. Fertil Steril 2002

the same conditions. This increment in Bcl-2 expression is related to the lower level of apoptosis in patients with EDT (Table 1 and Fig. 4A). These data confirm our recently published work (8).

We observed a drop in the expression of Bcl-2 in patients with EDT after exposure to COCs, which goes along with the endometrial atrophy observed histologically (Table 1). The expression profile of $\mathrm{Bcl}-2$ after COC administration is similar to the one observed in controls, which indicates that this protein would be involved in the regulation of apoptosis. In agreement with our previous work (8), we observed a lack 


\section{TABLE 1}

$\mathrm{Bcl}-2$ and Bax expression in the eutopic endometrium.

\begin{tabular}{|c|c|c|c|c|c|}
\hline \multirow[b]{2}{*}{ Case no. } & \multirow[b]{2}{*}{ EDT/Control } & \multicolumn{2}{|c|}{ Bax } & \multicolumn{2}{|c|}{ Bcl-2 } \\
\hline & & PRE & POST & PRE & POST \\
\hline 1 & Control & - & & ++ & \\
\hline 2 & Control & + & & + & \\
\hline 3 & Control & - & & ++ & \\
\hline 4 & Control & - & & & \\
\hline 5 & Control & - & & - & \\
\hline 6 & Control & - & & - & \\
\hline 7 & Control & - & & + & \\
\hline 8 & Control & + & & - & \\
\hline 9 & Control & - & & + & \\
\hline 10 & Control & ++ & & - & \\
\hline 11 & Control & - & & ++ & \\
\hline 12 & Control & - & & ++ & \\
\hline 13 & Control & - & & + & \\
\hline 14 & EDT III & - & +++ & +++ & + \\
\hline 15 & EDT III & + & ++ & + & - \\
\hline 16 & EDT I & - & +++ & ++ & - \\
\hline 17 & EDT I & - & +++ & +++ & + \\
\hline 18 & EDT II & - & ++ & +++ & ++ \\
\hline 19 & EDT II & - & - & +++ & + \\
\hline 20 & EDT II & - & +++ & +++ & + \\
\hline 21 & EDT II & - & & ++ & \\
\hline 22 & EDT II & - & ++ & +++ & - \\
\hline 23 & EDT II & - & & +++ & \\
\hline 24 & EDT III & - & ++ & +++ & + \\
\hline 25 & EDT II & - & ++ & + & - \\
\hline 26 & EDT III & + & + & ++ & ++ \\
\hline
\end{tabular}

Note: $\mathrm{EDT}=$ endometriosis; PRE $=$ before $\mathrm{COC}$ administration; POST $=$ after $\mathrm{COC}$ administration. Bcl-2 and Bax immunostaining were semiquantified by staining grade according to the following scale: $(-)$ negative, $(+)$ weakly positive, $(++)$ positive, and $(+++)$ strongly positive. A blank entry indicates no sample.

Meresman. Oral contraceptives and endometriosis. Fertil Steril 2002.

of expression of Bax in the majority of tissue samples from EDT and controls during the proliferative phase (Table 1).

Exposure to COCs resulted in a remarkable increase in the expression of Bax in endometrium from patients with EDT, which goes along with the increased apoptosis reported above (Table 1 and Fig. 4B). Finally, we could not establish a correlation in patients with EDT between the staging of EDT and the expression of Bcl-2-Bax in the eutopic endometrium.

\section{DISCUSSION}

The etiopathogenesis of EDT remains controversial, yet the most accepted theory assumes that the endometriotic implants originate by the migration of eutopic endometrial cells through retrograde transtubal flow into the peritoneal cavity of menstrual debris, with future implantation and growth on an ectopic site (17). Despite the fact that this theory gives the eutopic endometrium a fundamental role in
FIGURE 4

$A$ and $B$ are sections immunostained for $\mathrm{Bcl}-2$ and $\mathrm{Bax}$ protein expression. Bcl-2 protein expression in proliferative endometrium from a patient with EDT before administering COCs, magnification $\times 400$ (A). Bax protein expression in the endometrium from the same patient after administration of COCs, magnification $\times 400$. Note the strong immunopositivity in endometrial sections.
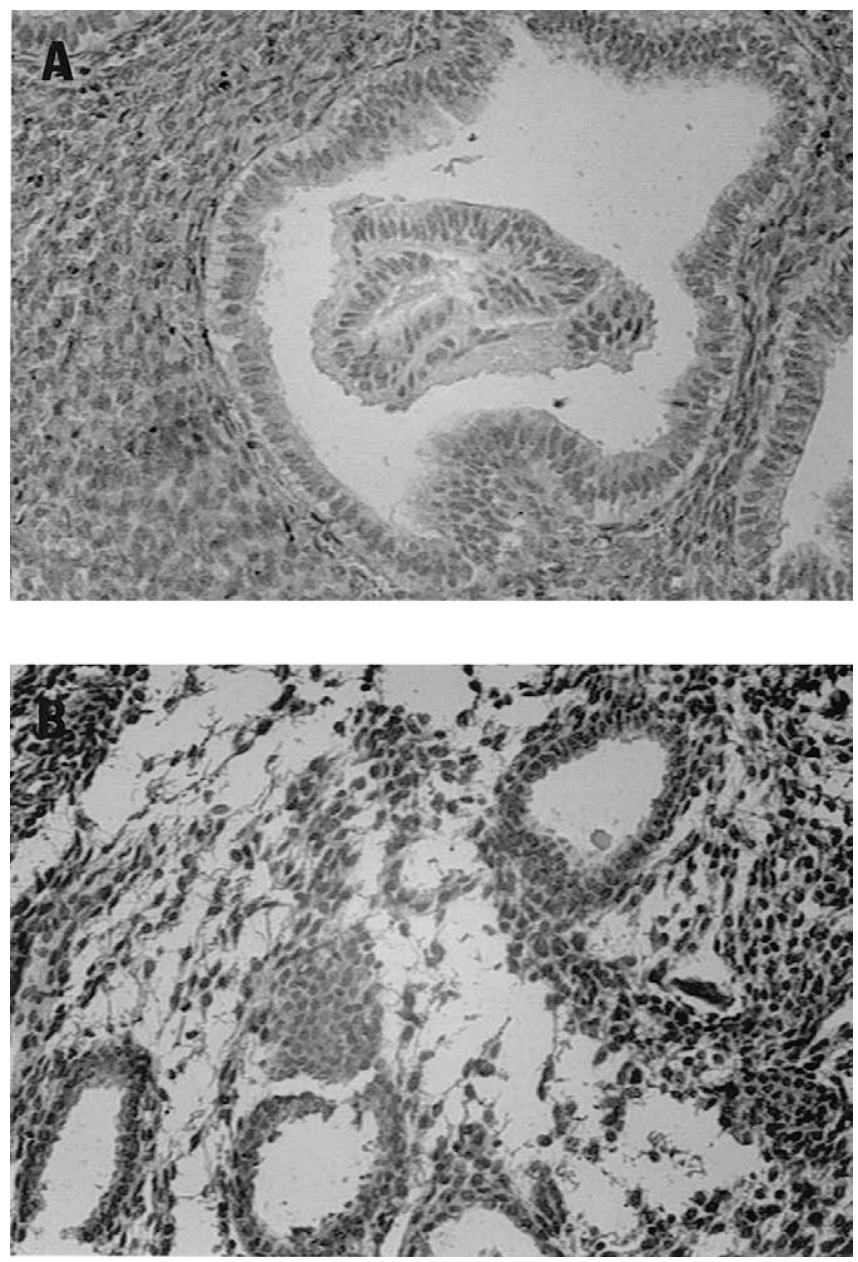

Meresman. Oral contraceptives and endometriosis. Fertil Steril 2002.

the pathogenesis of this disease, much has to be learned as to why only certain patients develop EDT, despite the fact that retrograde menstrual flow into the peritoneal cavity is such a common event (18).

In a recent publication, we showed a significant decrease in apoptosis in the eutopic endometrium from patients with EDT (8). The low levels of apoptosis observed by our group in the EP and ST was described for the whole endometrium by Dmowski et al., who proposed that survival of endometrial cells misplaced in ectopic locations may depend in part on the inherent ability of the cells to undergo apoptosis (19). 
The present study, besides corroborating our previous results, showed an increase in the cellular proliferation, both at the EP and ST levels, in the eutopic endometrium from patients with EDT. These findings suggest that besides a low degree of apoptosis in the eutopic endometrium from EDT, there is also increased cell proliferation. Such conditions facilitate the tissue survival and future growth in an ectopic site. This increased proliferation in the eutopic endometrium from patients with EDT was also described by Wigfield et al. (20), although Scotti and coworkers were unable to find differences in cell proliferation between patients with EDT and controls (21). It is unclear whether these abnormal findings in the eutopic endometrium from patients with EDT are primary in origin and significantly contribute to the development of the disease or secondary in nature to an established pelvic EDT process. Furthermore, the implications of an increased proliferation and decreased apoptosis at the local level and on a long-term basis are unknown, although the regular sloughing of the endometrium during menses prevents accumulation of the hyperproliferated endometrium. Also, it is known that the incidence of premalignant or malignant endometrial lesions is not increased in patients with EDT.

Short-term exposure to COCs histologically changed the endometrium, causing scanty proliferation, with the presence of few small glands (14). Our work showed that only 1 month of treatment with COCs was enough to induce a significant drop in the expression of the Ki-67 protein in the eutopic endometrium from patients with EDT compared with the same tissue before COC administration. This drop in cell proliferation shows levels similar to those observed in control patients during the midproliferative phase. Furthermore, the improvement in apoptotic index observed after COC administration in patients with EDT was comparable to that in control patients.

The immunohistochemical studies of the proteins involved in the regulation of apoptosis revealed a difference in the expression of Bax and Bcl-2 in the endometrium after COC administration. The increase in Bax expression and the drop in the expression of Bcl-2 would be the factors responsible for the resulting increase in apoptosis in EDT after COC administration.

The role of estrogens as stimulators of endometrial cell proliferation, in vivo (14) as well as in vitro (22), is well known, yet the molecular mechanism by which the sex steroids regulate endometrial growth is not clearly defined. Rider et al. (23) proposed that estrogens would be essential for the synthesis of P receptors and growth factors, which are needed for the passage from cell phase G0 to G1. We observed a profile in Bcl-2 after COC administration that was similar to the one observed in controls at the midproliferative phase, which suggests that this protein is involved in the regulation of cellular endometrial growth demonstrated in patients with EDT after COC administration.
The histological studies performed in the past indicated that COCs promoted an arrest in endometrial gland proliferation and that their long-term use resulted in progressive atrophy of the endometrium (16). Ovarian inactivation and moderately low estrogen concentration, obtained from cyclic monophasic COCs (24), may be beneficial as prophylactic regimens to delay or prevent the recurrence of EDT (25). Muzii et al. (26) reported in a placebo-controlled study that in patients with surgically treated endometriomas who were given COCs postoperatively for 6 months this treatment was superior to placebo in preventing recurrence of EDT at 1 year.

Whether the beneficial effects caused by COCs are exerted mainly through changes at the eutopic endometrial level as described in this report or perhaps through decreased inflammatory changes achieved by lowering the interleukins concentrations in peritoneal fluid, as recently described by Mahnke et al. (27), or by a combination of these mechanisms or an alternative mechanism remains to be determined.

Furthermore, recent publications have confirmed the inhibitory effect of progestogens on endometrial proliferation (28) and suggest that these compounds enhance apoptosis on the same tissue (29). Clinically, these medications have been shown to be of value in treating EDT, either alone (30) or as an estrogen-progestin combination (31).

In summary, from our results we can speculate that COCs would have a positive effect on patients with EDT by downregulating cell proliferation and enhancing programmed cell death in the eutopic endometrium, two factors possibly involved in the growth and/or recurrence of EDT.

\section{References}

1. Dahmoun M, Boman K, Cajander S, Westin P, Bäckström T. Apoptosis, proliferation and sex hormone receptors in superficial parts of human endometrium at the end of the secretory phase. J Clin Endocrinol Metab 1999;84:1737-43.

2. Hopwood D, Levinson DA. Atrophy and apoptosis in the cyclical human endometrium. J Pathol 1975;119:159-66.

3. Schwartzman RA, Cidlowski JA. Apoptosis: the biochemistry and molecular biology of programmed cell death. Endocrinol Rev 1993;14: 133-51.

4. Nawaz S, Lynch MP, Galand P, Gerschenson LE. Hormonal regulation of cell death in rabbit uterine epithelium. Am J Pathol 1987;127:51-9.

5. Sandow BA, West NB, Norman RN, Brenner RB. Hormonal control of apoptosis in hamster uterine luminal epithelium. Am J Anat 1979;156: $15-36$.

6. Slayden OD, Hirst JJ, Brenner RM. Estrogen action in reproductive tract of rhesus monkeys during antiprogestin treatment. Endocrinology 1993; 132:1845-56.

7. Spencer SJ, Cataldo NA, Jaffe RB. Apoptosis in the human female reproductive tract. Obstet Gynecol Surv 1996;51:314-23.

8. Meresman GF, Vighi S, Buquet RA, Contreras-Ortiz O, Tesone M, Rumi LS. Apoptosis and expression of Bcl-2 and Bax in eutopic endometrium from women with endometriosis. Fertil Steril 2000;74: $760-6$.

9. Nunez G, Clarke MF. The Bcl-2 family of proteins: regulators of cell death and survival. Trends Cell Biol 1994;4:399-403.

10. Oltvai ZN, Milliman CL, Korsmeyer ST. Bcl-2 heterodimerises in vivo with a conserved homologue Bax that accelerates programmed cell death. Cell 1993;74:609-19.

11. Garcia-Velasco JA, Arici A. Is the endometrium or oocyte/embryo affected in endometriosis? Hum Reprod 1999;14(Suppl 2):77-89.

12. Lessey BA. Medical management of endometriosis and infertility. Fertil Steril 2000;73:1089-96.

13. Vercellini P, Ragni G, Trespidi L, Colombo A, Vendola N, Marchini $\mathrm{M}$, et al. A gonadotropin releasing hormone agonist vs. a low dose oral 
contraceptive for pelvic pain associated with endometriosis. Fertil Steril 1993;60:75-9.

14. Deligdisch L. Hormonal pathology of the endometrium. Mod Pathol 2000;13:285-94.

15. Meresman GF, Barañao RI, Tenenbaum A, Singla JJ, Neuspiller NR, Rumi LS. Effect of peritoneal fluid from patients with minimal and severe endometriosis on endometrial stromal cell proliferation. Arch Gynecol Obstet 1997;259:109-15.

16. Koh EAT, Illingworth PJ, Duncan WC, Critchley HOD. Immunolocalization of Bcl-2 protein in human endometrium in the menstrual cycle and stimulated early pregnancy. Hum Reprod 1995;10:1557-62.

17. Sampson JA. Peritoneal endometriosis due to menstrual dissemination of endometrial tissue into the peritoneal cavity. Am J Obstet Gynecol $1927 ; 14: 422$

18. Liu DT, Hitchcock A. Endometriosis: its association with retrograde menstruation, dysmenorrhoea and tubal pathology. Br J Obstet Gynaecol 1986;93:859-62.

19. Dmowski WP, Gebel H, Braun DP. Decreased apoptosis and sensitivity to macrophage mediated cytolysis of endometrial cells in endometriosis. Hum Reprod Update 1998;4:696-701.

20. Wigfield M, Macpherson A, Healy D, Rogers P. Cell proliferation is increased in the endometrium of women with endometriosis. Fertil Steril 1995;64:340-6.

21. Scotti S, Regidor PA, Schindler AE, Winterhager E. Reduced proliferation and cell adhesion in endometriosis. Mol Hum Reprod 2000;6: $610-7$.

22. Pierro E, Minici F, Alesiani O, Miceli F, Proto C, Screpanti I, et al. Stromal-epithelial interactions modulate estrogen responsiveness in normal human endometrium. Biol Reprod 2001;64:831-8.
23. Rider V, Kimler BF, Justice WM. Progesterone-growth factor interactions in uterine stromal cells. Biol Reprod 1998;59:464-9.

24. Spellacy WN, Kalra PS, Buhi WC, Birk SA. Pituitary and ovarian responsiveness to a graded gonadotropin releasing factor stimulation test in women using a low dose or a regular type of oral contraceptive. Am J Obstet Gynecol 1980;137:109-15.

25. Bergqvist IA. Hormonal regulation of endometriosis and the rational and effects of GnRH-a treatment: a review. Hum Reprod 1995,10:44652.

26. Muzii L, Marana R, Carvana P, Catalano G, Margutti F, Panici P. Postoperative administration of monophasic combined oral contraceptives after laparoscopic treatment of ovarian endometriomas: a prospective, randomized trial. Am J Obstet Gynecol 2000;183:588-92.

27. Mahnke J, Dawood Y, Huang J. Vascular endothelial growth factor and interleukin-6 in peritoneal fluid of women with endometriosis. Fertil Steril 2000;73:166-70.

28. Moyer DL, Felix JC. The effects of progesterone and progestins on endometrial proliferation. Contraception 1998;57:399-403.

29. Critchley HOD, Tong S, Cameron ST, Drudy TA, Kelly RW, Baird DT. Regulation of bcl-2 gene family members in human endometrium by antiprogestin administration in vivo. J Reprod Fertil 1999;115:38995 .

30. Fedele L, Bianchi S, Zanconato G, Portuese A, Raffaelli R. Use of a levonorgestrel-releasing intrauterine device in the treatment of rectovaginal endometriosis. Fertil Steril 2001;75:485-8.

31. Moghissi KS. Treatment of endometriosis with estrogen-progestogen combination and progestogen alone. Clin Obstet Gynecol 1988; $31: 823-8$ 